\title{
Online monitoring of coffee roasting by proton transfer reaction time-of-flight mass spectrometry (PTR-ToF-MS): towards a real-time process control for a consistent roast profile
}

\author{
Flurin Wieland • Alexia N. Gloess • Marco Keller • \\ Andreas Wetzel • Stefan Schenker • Chahan Yeretzian
}

Received: 30 July 2011 /Revised: 5 September 2011 / Accepted: 6 September 2011 / Published online: 23 September 2011

(C) Springer-Verlag 2011

\begin{abstract}
A real-time automated process control tool for coffee roasting is presented to consistently and accurately achieve a targeted roast degree. It is based on the online monitoring of volatile organic compounds (VOC) in the off-gas of a drum roaster by proton transfer reaction timeof-flight mass spectrometry at a high time $(1 \mathrm{~Hz})$ and mass resolution $(5,500 \mathrm{~m} / \Delta \mathrm{m}$ at full width at half-maximum) and high sensitivity (better than parts per billion by volume). Forty-two roasting experiments were performed with the drum roaster being operated either on a low, medium or high hot-air inlet temperature (= energy input) and the coffee (Arabica from Antigua, Guatemala) being roasted to low, medium or dark roast degrees. A principal component analysis (PCA) discriminated, for each one of the three hotair inlet temperatures, the roast degree with a resolution of better than \pm 1 Colorette. The $3 \mathrm{D}$ space of the three first principal components was defined based on 23 mass spectral profiles of VOCs and their roast degree at the end point of roasting. This provided a very detailed picture of the evolution of the roasting process and allowed establishment of a predictive model that projects the onlinemonitored VOC profile of the roaster off-gas in real time onto the PCA space defined by the calibration process and,
\end{abstract}

Published in the special issue Analytical Sciences in Switzerland with guest editors P. Dittrich, D. Günther, G. Hopfgartner, and R. Zenobi.

F. Wieland $\cdot$ A. N. Gloess $\cdot$ C. Yeretzian $(\bowtie)$

Zurich University of Applied Sciences,

Institute of Chemistry and Biological Chemistry,

8820 Wädenswil, Switzerland

e-mail: yere@zhaw.ch

M. Keller $\cdot$ A. Wetzel $\cdot$ S. Schenker

Bühler AG,

Gupfenstrasse 5,

9240 Uzwil, Switzerland ultimately, to control the coffee roasting process so as to achieve a target roast degree and a consistent roasting.

Keywords Process analysis · Foods · Beverages · Gas sensors · Quality assurance/control · Sampling · Agriculture

\section{Introduction}

Coffee is the second most valuable commodity exported by developing countries - second to crude oil [1]. With an annual production in 2010 of 133 million bags $(60 \mathrm{~kg} / \mathrm{bag})$ and an average price of US $\$ 4.45$ per kilogram (According to the International Coffee Organization, composite price indicator, March 2011), this amounts to a total value of worldwide traded coffee in 2010 of $133 \times 10^{6} \mathrm{bags} \times 60 \mathrm{~kg} /$ bag $\times$ US $\$ 4.45 / \mathrm{kg}=$ US $\$ 35$ billion. Coffee is a commodity of high economic importance for coffee-producing as well as for coffee-consuming countries. Most remarkably, coffee has been, next to cotton, the second best performing commodity of 2010 - which has logged an impressive $45 \%$ return in 2010. Coffee is going for the highest price in nearly 14 years. There is no doubt that green coffee is a crop of global economic importance.

Yet, a green coffee bean is nearly flavourless. Whilst it contains all the ingredients necessary for the later development of the coffee flavour, it has to be roasted first to unlock its potential. Roasting is a crucial processing step that defines whether this potential is indeed expressed in the cup and materializes also in economic terms. Particularly in times of high commodity prices, and when dealing with high-quality specialty coffee, it is becoming indispensable to consistently master the roasting process in order to get the most out of an ever increasingly valuable crop. 


\section{Coffee roasting}

Roasting induces a range of physical and chemical transformation to the green coffee. Visible and physical changes include colour, texture, density and size. Furthermore, and most importantly, the typical coffee flavour is generated during the roasting process.

Once a specific roasting process for a given product has been optimized and a target final flavour established, a central quality criterion of a good roast is consistency, roast after roast. A consistent flavour profile is the outcome of a high mastery of the roasting process and an important feature of high-quality specialty coffee. It also decides whether a roasted batch is classified as either in or out of specifications, with obvious economic implications.

Consistency can be defined by establishing a target and assessing the performance of each roast relative to the target, the target being defined with measurable attributes that reflect the flavour profile of the roasted coffee. In order to deliver a consistent flavour profile, it is crucial to ensure a tight and precise control of the roasting process (in addition to a proper raw material selection and quality control). If small batches are roasted, the roast master most often uses a set of auditory and sensory indicators and personal experience to control the process. With larger batches of modern industrial roasters, the roast master mainly controls the process by the time-temperature profile and relies on physical measurements of the roast degree at the end point of the process to eventually make small adjustments. Physical measurements most often consist in measuring the colour of the roasted ground beans and the weight loss during roasting. Yet, both colour and weight loss are only indirect indicators of the flavour profile and hardly take into account that the formation of the coffee flavour during roasting depends on the full time-temperature history. Most notably, they are determined only after completion of the roasting process and do not allow acting on the actual process to improve the consistency of the result. The influence of the full time-temperature history on the formation of the coffee flavour during roasting was studied by Schenker et al. [2] and Baggenstoss et al. [3]. Performing different time-temperature roasting profiles, they monitored the flavour formation of coffee by taking samples at regular intervals during the roast process and analysed the coffee aroma compounds with gas chromatography-mass spectrometry. Their studies clearly showed that the formation of aroma is a function of the timetemperature conditions in the roaster. Results from Moon and Shibamoto [4] confirm these findings. However, all these studies did not perform an online analysis of the roasting process.

The objective of this research was to develop a technology that provides real-time information about the evolution of the roasting process based on criteria that are closely related to the aroma of coffee. This ensures the highest consistency of the roast degree, batch after batch, and hence improves the quality of roasted coffee.

Online real-time analysis of coffee off-gas

The approach proposed here is the online monitoring of the volatile organic compounds (VOCs) in the roaster off-gas and relating these to the flavour profile and the roast degree based on a large set of trials.

Roast gas is composed of a complex mixture of gases. These are primarily non-odorous inorganic gases such as $\mathrm{CO}_{2}, \mathrm{CO}, \mathrm{N}_{2}$ and $\mathrm{H}_{2} \mathrm{O}$ [5]; less than $1 \%$ volume of the gases are VOCs, a fraction of which represents coffee flavour compounds. In order to monitor in real time detailed flavour-relevant information on the evolution of the coffee roasting process, one needs methods capable of monitoring VOCs at high time resolution, with high sensitivity and chemical selectivity in the off-gas of a roaster.

Several techniques can be envisaged. One approach consists in using sensor arrays which exhibit different response patterns to the chemicals in the process gas. These so-called electronic noses have been applied with limited success to the characterization of food products [6]. Particularly for online analysis of complex and fast processes, such as coffee roasting, its usefulness is presently very limited. The most serious limitations of the current systems can be (1) low time resolution, (2) difficulty to relate the observed signal to relevant quality criteria in the cup, (3) drift in sensor responses or (4) lack of sensitivity.

Another approach is direct inlet mass spectrometry (DIMS). In a recent review, the advantages and limitations of various direct inlet MS methods were discussed [7]. A prerequisite for mass analysis is ionization. Electron impact ionization causes considerable fragmentation. Because of overlapping fragment and parent ions, the molecular information is difficult to deconvolute, and little chemical information can be obtained. Nevertheless, and relative to e-nose technologies, such an approach will achieve high time resolution and sensitivity, and high specificity of the chemical information, e.g. for typical combustion gases such as $\mathrm{CO}, \mathrm{CO}_{2}, \mathrm{~N}_{2}$ or $\mathrm{H}_{2} \mathrm{O}$.

In contrast, the application of chemical ionization in combination with direct inlet MS for the analysis of VOCs produces little or no fragmentation (soft ionization). Atmospheric pressure chemical ionization mass spectrometry (APCI-MS) [8-12] and proton transfer reaction mass spectrometry (PTR-MS) [13-20], both equipped with a quadrupole mass filter, have been successfully applied to the online and fast analysis of complex VOC mixtures. 
An alternative to chemical ionization is selective and soft laser photo ionization using either resonance-enhanced two photon ionization (RE2PI) or vacuum UV single-photon ionization (VUV-SPI) [21-29]. RE2PI exhibits a very selective ionization, depending on the functionality and structure of the VOC. It has a very high sensitivity for phenolic and heterocylic aromatic compounds and a very low ionization cross-section for aliphatic molecules. VUVSPI has similarities to PTR-MS as it is a threshold ionization method. All compounds with a photoionization cross-section below the VUV photon energy are effectively ionized in the one-photon ionization process, similar to threshold ionization in PTR-MS by proton transfer from $\mathrm{H}_{3} \mathrm{O}^{+}$.

Applications of DIMS to the analysis of coffee roasting

Various DIMS technologies have already been applied to monitor online the off-gas during coffee roasting. Already in 1996, the first of a series of exploratory studies using RE2PI-time-of-flight mass spectrometry (ToF-MS) was published [24, 25, 29, 30]. The coffee roasting process was analysed by direct injection of the roaster gas into a time-of-flight mass spectrometer and ionized either by RE2PI at 266 and $248 \mathrm{~nm}$ or VUV-SPI at $118 \mathrm{~nm}$. The VUV ionization scheme allowed detecting mainly the most volatile and abundant compounds of molecular mass below $100 \mathrm{~m} / \mathrm{z}$, whilst RE2PI ionizes selectively mainly aromatic compounds of molecular mass larger than $100 \mathrm{~m} / \mathrm{z}$. Combining both ionization schemes, 30 VOCs were monitored in real time. The time-intensity profiles of ten important volatile coffee compounds were discussed in connection with their formation chemistry during roasting. Furthermore, applying multivariate statistics on the timeintensity traces of nine volatile coffee compounds, the roasting degree could be roughly traced for a range of roasting temperatures $\left(200-250{ }^{\circ} \mathrm{C}\right)$. This study demonstrated that online control of the coffee roasting process is technically feasible. Yet it lacked a tight control of the roasting process. [24]. In a separate study, RE2PI-ToF-MS at $266 \mathrm{~nm}$ was applied to discuss in more detail the dynamic formation mechanism of 4-vinylguaiacol and guaiacol during roasting. This work specifically addressed the possibilities of developing roasting strategies to modify the composition of coffee flavour compounds based on the understanding and, eventually, control of their timetemperature formation history during roasting [25].

Later, in 1998, the coffee roasting process was investigated by an emerging alternative online technology, PTRMS [31-33]. Using a self-made experimental lab roaster that allowed only for a rough control of the roasting conditions, $40 \mathrm{~g}$ of green coffee beans was roasted at approximately 180,185 and $190{ }^{\circ} \mathrm{C}$. Monitoring the time- intensity profiles for a large number of VOCs, the various stages of the roasting process and their transitions could be observed. In a second series of experiments, just six beans were roasted to investigate the phenomena occurring at the single bean level. In coincidence with popping sounds from the beans, sharp bursts of some volatiles were reported. This work revealed interesting phenomena for the release of VOC occurring at the level of individual beans. Furthermore, it demonstrated the potential of PTR-MS for online process monitoring of the roasting process via off-gas analysis [31].

In this work, we applied proton transfer reaction time-offlight mass spectrometry (PTR-ToF-MS) to the online analysis of the roaster off-gas. Referring to former work with RE2PI-ToF-MS, VUV-ToF-MS and PTR-MS, here, we focused on a very tight control and stability of the roasting process using an industrial drum roaster. For three specific hot-air inlet temperatures, a series of 42 different roasting experiments were performed. A principal components analysis (PCA) based on the VOC profiles at the end point of the roasting processes led to the construction of a 3D space, defined by the first three principal components. This was subsequently used as a basis for a real-time process control tool.

\section{Material and methods}

\section{Green coffee}

All roasting experiments were performed on the green coffee species Coffea arabica L. (hereinafter called Arabica) from Guatemala, from the growing region of Antigua (2010 harvest). The green coffee was from Rast Kaffee AG (www.rast.ch) in Ebikon, Switzerland, a blend of the two varieties Bourbon and Pache Común, a SHB (strictly high bean) washed coffee of mesh size 17/18, grown at an altitude of $1,500 \mathrm{~m}$. The high altitude, mild weather, volcanic soils and eternal spring-like conditions provide the setting to produce an excellent specialty coffee known as 'Antigua La Ceiba' (harvesting time: October to March).

\section{Coffee roaster}

A Petroncini TT $15 / 20$ drum coffee roaster with a capacity of 15-20 kg per batch, heated by gas, was used. The off-gas was actively drawn out of the drum with a ventilation system and blown into the cyclone, where the silver skins from the beans were separated. At the end of each roasting cycle, beans were cooled by air quenching. To monitor and control the roasting process, the roaster was fitted with several sensors and controllers, as shown in Fig. 1a-c. Three temperature sensors measured the respective temper- 
Fig. 1 The Petroncini TT 15/20 drum roaster and the setup for online sampling of the roaster off-gas by PTR-ToF-MS. The top frames $(\mathbf{a}-\mathbf{c})$ show three views of the roaster with the locations of temperature and flow meters: a Rear view with sensor $T_{1}$ monitoring the temperature of the heating gas entering the roasting drum. b Side view with the sensor $T_{3}$ for the off-gas temperature and the flow meters for the heating gas, $F_{\mathrm{HG}}$, and the off-gas, $F_{\mathrm{OG}}$. $\mathbf{c}$ Front view with sensor $T_{2}$ to monitor the temperature inside the roaster. This view also shows the PTR-ToF-MS behind the roaster with the sampling line for the off-gas. The bottom frame shows a schematic of the coupling of the roaster with the PTR-ToF-MS

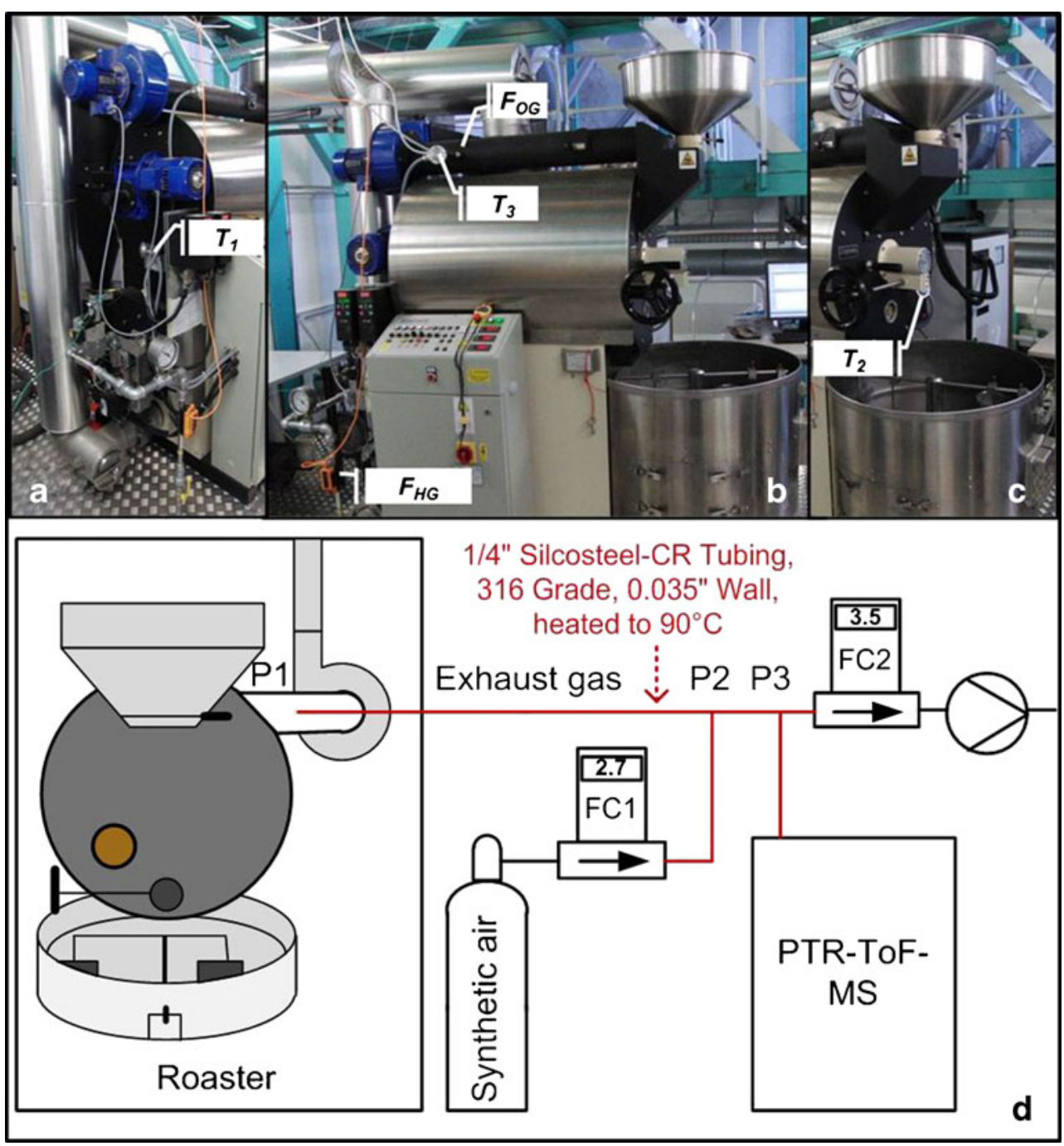

ature profiles for each roasting cycle, one situated in the heating gas entering the roasting drum $\left(T_{1}\right.$; Fig. 1a), a second inside the drum $\left(T_{2}\right.$; Fig. 1c) and a third in the offgas $\left(T_{3}\right.$; Fig. 1b). These were complemented by a mass flow meter $\left(F_{\mathrm{HG}}\right.$; Fig. $\left.1 b\right)$ on the supply side of the heating gas line and a second mass flow meter $\left(F_{\mathrm{OG}}\right.$; Fig. $\left.1 b\right)$ in the off-gas line.

\section{Coffee roasting experiments}

Batches of $15.6 \mathrm{~kg}$ green coffee were roasted at three different hot-air inlet temperatures (high, medium and low) each to three roasting degrees (dark, medium and light). Every step of a roasting cycle was conducted along a welldefined and fixed procedure to achieve high stability and consistency for each roasting cycle, batch after batch, as described below.

Prior to the roasting trials, the roaster was conditioned with five cycles in order to ensure stable roasting conditions and reproducible PTR-ToF-MS data. The coffee was ground on a Stawert Mahlkönig VTA6S grinder with tungsten carbide flat discs (grinder setting, 7).

The target roasting degrees were based on the Minolta CR300 colour $L$ values. The $L$ values are specified by the luminance $L$ in the CIE colour system, whereby $L$ ranges from 0 (pure black) to 100 (pure white). After calibration of the colorimeter using the instrument's white plates, the $L$ values of the samples were obtained by measuring the coffee powder directly in 50-mm (diameter) cells. In addition to the Minolta values, the roast degree was also expressed in Colorette values, as provided from a Probat Colorette $3 \mathrm{~b}$ from Probat-Werke von Gimborn Maschinenfabrik GmbH. Both scales are related by a linear regression: Colorette $=f(L$ value $)=17.624 \times L$ value $-619.37 ; R^{2}=0.992$.

Proton transfer reaction time-of-flight mass spectrometry

The PTR TOF 8000 from Ionicon Analytik GmbH (Innsbruck/ Austria) is a commercially available instrument constructed from interfacing the high-sensitivity proton transfer reaction 
instrument from Ionicon, composed of a hollow cathode ion source and a drift tube section, with a compact, orthogonal reflectron time-of-flight mass spectrometer from Tofwerk AG in (Thun/Switzerland). The PTR-ToF-MS achieves a detection limit of 20 pptv for a 1-min integration time (better than parts per billion by volume for $1 \mathrm{~s}$ ) and a mass resolution of up to $5,500 \mathrm{~m} / \Delta \mathrm{m}$ (full width at half-maximum, FWHM). It is mounted on a single mobile rack where the mass spectrometer, the ion source and drift tube system, the vacuum system (two split-flow turbo pumps and one foreline backing pump) and the whole electronics, including the pulse generator, are integrated. The rack dimensions are $55 \times 130 \times 78 \mathrm{~cm}(W \times H \times D)$ and the whole instrument weighs approximately $170 \mathrm{~kg}$. The data acquisition and analysis system is situated in an external desktop computer and display system. In the hollow cathode ion source, $\mathrm{H}_{3} \mathrm{O}^{+}$reagent ions are produced from water vapour $(4 \mathrm{sccm})$ introduced as a reagent gas from a liquid water sample holder. Reagent ions are entering the adjacent drift tube section where the sample to be analysed is continuously injected via a gas inlet system with adjustable flow between 50 and $1,000 \mathrm{sccm}$ and adjustable temperature between 40 and $150{ }^{\circ} \mathrm{C}$. The actual flow and temperature were set throughout all experiments at $200 \mathrm{sccm}, 80^{\circ} \mathrm{C}$.

In the drift tube $\left(2.2 \mathrm{mbar} ; 600 \mathrm{~V}, 80^{\circ} \mathrm{C}\right)$, the proton transfer reactions occur between hydronium ions and neutral VOCs. The outgoing protonated VOC ions are transferred via a specially designed transfer lens system to the pulsed extraction region of the orthogonal reflector time-of-flight mass spectrometer. With a ToF extraction frequency of $30 \mathrm{kHz}$ and an acquisition rate of $1 \mathrm{~Hz}$ (averaging over 28,600 extraction pulses), a mass range $\mathrm{m} / \mathrm{z}$ of 10-423 was covered for each extraction pulse.

Experimental setup and online sampling of the roaster off-gas

A schematic of the sampling setup is shown in Fig. 1d. The roaster off-gas analysed by PTR-ToF-MS was actively sampled at position $\left(\mathrm{P}_{1}\right)$ from the exhaust line of the roaster off-gas by a vacuum pump and adjusted by the flow controller FC2 (Analyt-MTC, Germany). It was filtered through a fine PEEK mesh to prevent the capillary inlet system from solid contaminations such as dust or silver skins. To reduce the temperature, humidity and VOC concentrations in the gas being introduced into the chemical ionization cell of the PTR-ToF-MS, the sampled off-gas was diluted with synthetic air at $\mathrm{P}_{2}$, the dilution flow being adjusted by FC1 (dilution flow FC1, 2,700 sccm). The total flow after dilution was set by the FC2 at 3,500 $\mathrm{sccm}$. At point $\mathrm{P}_{3}$, a constant flow of only $200 \mathrm{sccm}$ is sampled into the drift tube for online analysis in the PTR-ToF-MS, whilst the remaining gas is released through $\mathrm{FC} 2$ and the pump. This led to an approximate dilution factor of 4. All flow controllers were calibrated by the supplier at the beginning of the trials.

Furthermore, online analysis of VOCs requires minimizing condensation along the sampling line to avoid memory effects and achieve high sensitivity and time resolution. Therefore, all 0.25 -in. transfer lines were deactivated fused-silica tubings (Silocosteel-CR, 316 grade by Restek), heated with heating bands to $90{ }^{\circ} \mathrm{C}$ and wrapped in isolating foamed material, whereby cold spots were avoided.

\section{Data analysis}

A major advantage of PTR-ToF-MS compared with PTRQuadrupole-MS is the high resolution with respect to time and mass, as well as improvements in sensitivity and mass range. Yet, this inevitably leads to a dramatic increase in the size of data files. To optimally extract relevant information from such huge databases (more than $20 \mathrm{MB}$ per measurement), a systematic process of data treatment, analysis and interpretation is necessary, as summarized in Fig. 2.

\section{Significant ions}

A PTR-ToF-MS spectrum contains hundreds of ion peaks, many of which are either redundant (e.g. isotopes) and some not related to the samples (e.g. $\mathrm{H}_{3} \mathrm{O}^{+}$from the ionization source). The first step was therefore the selection of significant ions to be included into the data

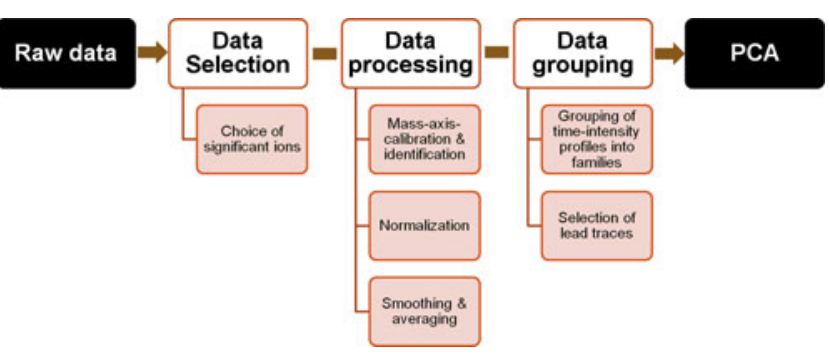

Fig. 2 The data analysis process can roughly be divided into five steps. Raw data: First experimental raw data are collected. This consists of online monitoring of the roasting off-gas and fast acquisition of PTRToF-MS data over the complete roasting process. Data selection: Considering that the aim of the work was to develop a fast, real-time process control tool for coffee roasting, redundant information is eliminated already at this stage. Data processing: The remaining data are transformed so that they can be analysed in a systematic way. This includes calibrating the $\mathrm{m} / \mathrm{z}$ mass axis, normalizing the time and intensity axes, and smoothing the time-intensity profiles. Data grouping: Here, again, redundant information is eliminated by grouping the time-intensity traces into family of identical profile and selecting from each family only the one (the most intense one, called the lead trace) to be included into the predictive model. This allowed developing an effective model for process control with the least amount of timeintensity traces. PCA: Finally, a principal component analysis is developed that allows monitoring and controlling the roasting process and the consistency of the roasted product 
analysis. Only signals of the most prominent isotopes with a time-intensity profile reaching an intensity of more than three times the standard deviation of the base line were included.

\section{Identification}

The transformation of time-of-flight into $\mathrm{m} / \mathrm{z}$, i.e. the calibration of the mass axis, was performed in a series of iterative steps. For each acquired ToF data set, three clearly identifiable ion signals $-\left[\mathrm{H}_{3} \mathrm{O}^{16} \mathrm{O}^{18}\right]^{+}$, protonated water cluster with one $\mathrm{O}^{18}$ isotope, $\left[\mathrm{NO}^{+}\right.$and $\left[\mathrm{C}_{3} \mathrm{H}_{7} \mathrm{O}\right]^{+}$ (acetone)-were selected and used to calibrate the low mass region of the $\mathrm{m} / \mathrm{z}$ axis, up to $60 \mathrm{~m} / \mathrm{z}$. This calibration of the $m / z$ axis in the low mass region was subsequently extrapolated to higher masses. A peak at about $20 \mathrm{~m} / \mathrm{z}$ larger than acetone was identified, the exact mass calculated and included into a second round of calibration of the $\mathrm{m} / \mathrm{z}$ axis. This improved and extended calibration was then used to further extrapolate the calibration of the $\mathrm{m} / \mathrm{z}$ axis by an additional $20 \mathrm{~m} / \mathrm{z}$ unit; a fifth compound was identified and included into a third round of improved calibration. Repeating this iteration several more times, the mass range $10-150 \mathrm{~m} / \mathrm{z}$ was accurately calibrated and all significant ions identified. At this stage, 63 ions were identified. Some were independent from the samples, such as $\mathrm{H}_{3} \mathrm{O}^{+}, \mathrm{H}_{3}{ }^{18} \mathrm{O}^{+}$, $\mathrm{O}_{2}{ }^{+}, \mathrm{NO}^{+}, \mathrm{H}_{5} \mathrm{O}_{2}{ }^{+}$, whilst 54 ions were selected (including $\mathrm{H}_{5} \mathrm{O}_{2}^{+}$) for further data evaluation.

\section{Normalization}

The intensity of the raw data was expressed in counts per seconds (cps). Cps are strongly dependent on the specific instrumental and experimental conditions and may vary among experiments. It is therefore imperative to normalize the data using an internal standard. One such 'natural' internal standard that ideally only depends on experimental conditions and is not affected by differences in the composition and concentration of samples is the primary $\mathrm{H}_{3} \mathrm{O}^{+}$and its isotopically substituted $\mathrm{H}_{3}{ }^{18} \mathrm{O}^{+}$ion. Since the intensity of $\mathrm{H}_{3} \mathrm{O}^{+}$may saturate the detector, the $\left[\mathrm{H}_{3}{ }^{18} \mathrm{O}\right]^{+}$intensity was used for normalization, multiplied by 500 (the factor 500 being approximately the isotope abundance ratio ${ }^{16} \mathrm{O} /{ }^{18} \mathrm{O}=99.72: 0.205 \%$ ). With that, intensities are normalized against $\mathrm{cps}_{\left[\mathrm{H}_{3} \mathrm{O}\right]^{+}} \times 10^{-6}$. Furthermore, to account for fluctuations in the flow of the roasting gas, the intensities were normalized against the mass of the roasting gas, $m_{\text {air }}$, based on the measured $F_{\mathrm{OG}}$. With that, we obtain the normalized counts per seconds (ncps) per kilogram air, as shown in Eq. 1:

$\mathrm{ncps}_{\text {Ion }} / k g=\frac{\operatorname{cps}_{I o n} \cdot 10^{6}}{\operatorname{cps}_{\left[\mathrm{H}_{3}{ }^{18} O\right]^{+}} \cdot 500 \cdot m_{\text {air }} \cdot F_{O G}}$

\section{Smoothing and averaging}

Data were smoothed using Friedman's 'smoother algorithm' [34] and averaged over the replicates in order to better identify similarities between the different timeintensity profiles of individual $\mathrm{m} / \mathrm{z}$ signals. Referring to Fig. 2, 'data grouping' and 'PCA' will be discussed in "Results and discussion".

\section{Results and discussion}

Characterisation of the roasting profiles and grouping of identical ion traces into families

In a first series, 42 roasting experiments were performed, 15 on low, 13 on medium and 14 on high hot-air inlet temperatures. Roasted coffee batches were included into the data analysis only if the roast degree deviated by less than \pm 1 Colorette from the target roast degree (Colorette 100, 91 and 78 for light, medium and dark roast, respectively). Table 1 summarizes the conditions under which the roasting experiments were conducted; the two-letter labelling was used throughout this work.

Figure 3 shows the experimentally measured time evolutions of $T_{2}$ for the various roasting profiles. It is important to clarify that $T_{2}$, the temperature measured inside the roaster, is neither the real bean temperature nor the real hot-air temperature in the drum. Whilst it is close to the actual product temperature, $T_{2}$ remains an approximation for it and is often used as an estimation of the real coffee temperature, whilst the link between the measured $T_{2}$ and the real temperature of the coffee depends on the roaster type and the process conditions and hence cannot be transferred from one roaster to another.

The full line represents the time-temperature trace at high hot-air inlet temperature. Depending whether beans were roasted to a light (HL), a medium (HM) or a dark (HD) roast degree, the roasting cycles were stopped at the indicated marks. The dashed and the dotted lines represent roasting experiments at medium and low hot-air inlet temperature, respectively.

A total of 54 time-intensity $\mathrm{m} / \mathrm{z}$ ion traces were analysed in detail; these are listed in Table 2 by their mass-to-charge ratio (Thomson). Forty-four of these traces could be classified into 15 distinct families of time-intensity patterns. All ion traces within a specific family have overlapping time-intensity patterns and hence reflect the identical (redundant) dynamic information about the roasting process. The most intense ion trace from each family is called the lead trace; the lead traces are highlighted in Table 2 (in bold). In addition, ten ion traces were distinct and could not be grouped into families (traces 16 to 25 in 
Table 1 Coffee was roasted applying three different hot-air inlet temperatures (L, low; M, medium; H, high), each to three different roast degrees (L, light; $\mathrm{M}$, medium; D, dark), yielding a total of nine different time-temperature roasting profiles, labelled by a two-letter code (first column)

\begin{tabular}{|c|c|c|c|c|c|c|c|c|c|c|}
\hline \multirow[t]{2}{*}{ Code } & \multirow{2}{*}{$\begin{array}{l}\text { No. of } \\
\text { trials }\end{array}$} & \multirow{2}{*}{$\begin{array}{l}\text { Hot-air inlet } \\
\text { temperature }\end{array}$} & \multirow{2}{*}{$\begin{array}{l}\text { Roast } \\
\text { degree }\end{array}$} & \multirow{2}{*}{$\begin{array}{l}\text { Roasting } \\
\text { time (s) }\end{array}$} & \multirow{2}{*}{$\begin{array}{l}\text { Roast } \\
\text { degree( } L \text { value })\end{array}$} & \multirow{2}{*}{$\begin{array}{l}\text { Roast degree } \\
\text { (Colorette) }\end{array}$} & \multirow{2}{*}{$\begin{array}{l}\text { Mean } \\
F_{\mathrm{OG}}\left(\mathrm{g} \mathrm{s}^{-1}\right)\end{array}$} & \multicolumn{3}{|c|}{ Mean values at the final time } \\
\hline & & & & & & & & $T_{1}\left({ }^{\circ} \mathrm{C}\right)$ & $T_{2}\left({ }^{\circ} \mathrm{C}\right)$ & $T_{3}\left({ }^{\circ} \mathrm{C}\right)$ \\
\hline LL & 4 & Low & Light & $1,130 \pm 25$ & $41.38 \pm 0.07$ & $109.9 \pm 1.2$ & $70.4 \pm 0.6$ & $316.5 \pm 0.9$ & $184.6 \pm 0.4$ & $179.1 \pm 0.5$ \\
\hline LM & 5 & Low & Medium & $1,199 \pm 9$ & $40.28 \pm 0.04$ & $90.4 \pm 0.7$ & $68.7 \pm 0.5$ & $321.0 \pm 1.2$ & $192.2 \pm 0.7$ & $185.2 \pm 0.7$ \\
\hline LD & 6 & Low & Dark & $1,258 \pm 11$ & $39.54 \pm 0.06$ & $77.5 \pm 1.1$ & $67.7 \pm 0.2$ & $327.0 \pm 1.4$ & $198.9 \pm 0.4$ & $189.0 \pm 0.3$ \\
\hline ML & 5 & Medium & Light & $831 \pm 1$ & $41.40 \pm 0.05$ & $110.3 \pm 0.9$ & $69.6 \pm 0.4$ & $368.3 \pm 0.4$ & $185.7 \pm 0.4$ & $183.1 \pm 0.5$ \\
\hline MM & 3 & Medium & Medium & $869 \pm 14$ & $40.31 \pm 0.03$ & $91.1 \pm 0.6$ & $70.2 \pm 0.5$ & $374.9 \pm 1.4$ & $192.7 \pm 0.5$ & $188.3 \pm 0.2$ \\
\hline MD & 5 & Medium & Dark & $907 \pm 3$ & $39.56 \pm 0.06$ & $77.8 \pm 1.0$ & $69.4 \pm 0.3$ & $380.2 \pm 0.6$ & $198.3 \pm 0.5$ & $191.9 \pm 0.2$ \\
\hline HL & 5 & High & Light & $546 \pm 7$ & $41.36 \pm 0.08$ & $109.5 \pm 1.4$ & $67.6 \pm 0.6$ & $462.4 \pm 1.2$ & $185.9 \pm 0.5$ & $185.4 \pm 0.4$ \\
\hline HM & 5 & High & Medium & $572 \pm 8$ & $40.31 \pm 0.07$ & $91.1 \pm 1.2$ & $67.1 \pm 0.5$ & $468.8 \pm 1.9$ & $191.4 \pm 0.6$ & $188.8 \pm 0.4$ \\
\hline HD & 4 & High & Dark & $593 \pm 8$ & $39.56 \pm 0.03$ & $77.9 \pm 0.5$ & $66.7 \pm 0.3$ & $472.6 \pm 0.9$ & $195.4 \pm 1.2$ & $191.1 \pm 0.7$ \\
\hline
\end{tabular}

For each profile, three to five roasting trials were performed (no. of trials). $F_{\mathrm{OG}}$ is the gas flow in the off-gas line. The three last columns give the values $T_{1}, T_{2}$ and $T_{3}$ for each roast profile as measured by the respective temperature sensors (see Fig. 1). Every roasting experiment was repeated five times, and all results are reported as the mean value and a $95 \%$ confidence level

Table 2). All together, this amounts to 25 distinct timeintensity patterns.

\section{Online analysis of the roaster off-gas by PTR-ToF-MS}

Figure 4 illustrates a typical data set for medium hot-air inlet temperature and dark roast (MD), corresponding to a total roasting time of $894 \mathrm{~s}(\sim 15 \mathrm{~min})$. The central frame shows the full time-intensity contour plot for the 23 traces, which were used for the predictive model, as will be described later. Until $500 \mathrm{~s}$, the intensities of the VOCs are low and hardly any of the typical coffee aroma compounds are observed. Between $500 \mathrm{~s}$ and up to close to the end of the roasting at $894 \mathrm{~s}$, the intensities of most ion traces increase strongly, reflecting the formation of the typical coffee aroma compounds. The top two frames show two

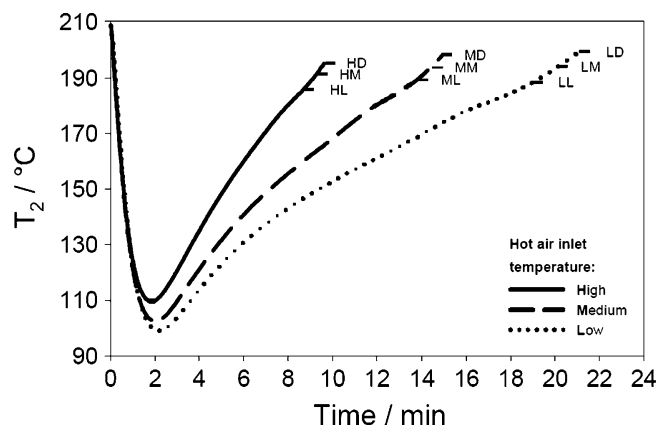

Fig. 3 Time-temperature profiles during the roasting experiments, as measured by $T_{2}$. All roasting experiments start at $210^{\circ} \mathrm{C}$. Filling in the beans into the drum leads to an immediate and sharp decrease of temperature inside the drum. Depending on the hot-air inlet temperature (High, Medium, Low), the temperature rises subsequently at different rates until the target end roasting temperature/roast degree is reached. $T_{2}$ represents a convoluted temperature trace between the actual bean temperature and the surrounding hot-air temperature
PTR-ToF-MS $m / z$ spectra in a logarithmic scale at those two specific points in time and are indicated in the central contour plot by two vertical bars at the respective times. Whilst the trace at $500 \mathrm{~s}$ has only a few ion signals at a lower molecular weight, the mass spectrum at the end of the roasting process (right top frame, 894 s) contains a large number of higher mass VOCs formed during roasting. The bottom frames represent horizontal cuts of the contour plot and show time-intensity profiles of two lead traces that have very different time-intensity patterns; the left frame shows the lead trace $\# 5\left(61.028\right.$ Th. $\left.\left[\mathrm{C}_{2} \mathrm{H}_{5} \mathrm{O}_{2}\right]^{+}\right)$, which was used for normalization. It starts to appear in the roaster offgas just before $500 \mathrm{~s}$, increases sharply until about $730 \mathrm{~s}$ and flattens into a plateau before rising again all the way to the end of the roasting process. The right frame shows lead trace \#24 (145.050 Th. $\left.\left[\mathrm{C}_{6} \mathrm{H}_{9} \mathrm{O}_{4}\right]^{+}\right)$and has a distinctively different time-intensity pattern. The ion appears at a slightly earlier time, already before $400 \mathrm{~s}$, increases gradually to reach an intensity maximum at about $730 \mathrm{~s}$ (same time as the plateau for family \#5) and decreases again to reach a very low level in the off-gas at the end of the roasting process.

Figure 5 illustrates the differences in the time-intensity profiles among the various lead traces based on four selected examples of roasting profiles. The dark black lines represent the ion traces for a light roast degree, the medium grey lines represent time-intensity profiles for medium roasted coffee, and light grey represents traces for a dark roast. For each hotair inlet temperature, the traces for the three roast degrees are essentially overlapping, demonstrating the very high reproducibility of the roasting profiles.

The top right frame shows the lead trace of family \#5, represented by a compound of the sum formula $\left[\mathrm{C}_{2} \mathrm{H}_{5} \mathrm{O}_{2}\right]^{+}$, and which was throughout all trials the most intense trace in 
Table 2 List of the relevant $54 \mathrm{~m} / \mathrm{z}$ ion peaks from the PTR-ToF-MS data (mass-to-charge ratio, Thomsen (Th.), sum formula), grouped into families

\begin{tabular}{|c|c|c|c|c|c|}
\hline Family/ion trace no. & Th. & Sum formula & $\mathrm{PC} 1 \mathrm{R}^{2}$ & $\mathrm{PC} 2 \mathrm{R}^{2}$ & PC3 $\mathrm{R}^{2}$ \\
\hline \multirow[t]{2}{*}{1} & 15.023 & {$\left[\mathrm{CH}_{3}\right]^{+}$} & 0.037 & 0.922 & 0.000 \\
\hline & 31.018 & {$\left[\mathrm{CH}_{3} \mathrm{O}\right]^{+}$} & - & - & - \\
\hline \multirow[t]{2}{*}{2} & 29.039 & {$\left[\mathrm{C}_{2} \mathrm{H}_{5}\right]^{+}$} & 0.048 & 0.752 & 0.000 \\
\hline & 60.021 & {$\left[\mathrm{C}_{2} \mathrm{H}_{4} \mathrm{O}_{2}\right]^{+}$} & - & - & - \\
\hline \multirow[t]{5}{*}{3} & 39.023 & {$\left[\mathrm{C}_{3} \mathrm{H}_{3}\right]^{+}$} & - & - & - \\
\hline & 41.039 & {$\left[\mathrm{C}_{3} \mathrm{H}_{5}\right]^{+}$} & 0.141 & 0.652 & 0.093 \\
\hline & 43.054 & {$\left[\mathrm{C}_{3} \mathrm{H}_{7}\right]^{+}$} & - & - & - \\
\hline & 49.011 & {$\left[\mathrm{CH}_{5} \mathrm{~S}\right]^{+}$} & - & - & - \\
\hline & 53.039 & {$\left[\mathrm{C}_{4} \mathrm{H}_{5}\right]^{+}$} & - & - & - \\
\hline \multirow[t]{2}{*}{4} & 42.010 & {$\left[\mathrm{C}_{2} \mathrm{H}_{2} \mathrm{O}\right]^{+}$} & - & - & - \\
\hline & 60.044 & {$\left[\mathrm{C}_{2} \mathrm{H}_{6} \mathrm{NO}\right]^{+}$} & 0.006 & 0.885 & 0.004 \\
\hline \multirow[t]{5}{*}{5} & 43.018 & {$\left[\mathrm{C}_{2} \mathrm{H}_{3} \mathrm{O}\right]^{+}$} & - & - & - \\
\hline & 57.033 & {$\left[\mathrm{C}_{3} \mathrm{H}_{5} \mathrm{O}\right]^{+}$} & - & - & - \\
\hline & 61.028 & {$\left[\mathrm{C}_{2} \mathrm{H}_{5} \mathrm{O}_{2}\right]^{+}$} & Normalization & Normalization & Normalization \\
\hline & 75.044 & {$\left[\mathrm{C}_{3} \mathrm{H}_{7} \mathrm{O}_{2}\right]^{+}$} & - & - & - \\
\hline & 103.075 & {$\left[\mathrm{C}_{5} \mathrm{H}_{11} \mathrm{O}_{2}\right]^{+}$} & - & - & - \\
\hline \multirow[t]{2}{*}{6} & 55.054 & {$\left[\mathrm{C}_{4} \mathrm{H}_{7}\right]^{+}$} & - & - & - \\
\hline & 59.049 & {$\left[\mathrm{C}_{3} \mathrm{H}_{7} \mathrm{O}\right]^{+}$} & 0.724 & 0.254 & 0.000 \\
\hline \multirow[t]{4}{*}{7} & 67.054 & {$\left[\mathrm{C}_{5} \mathrm{H}_{7}\right]^{+}$} & - & - & - \\
\hline & 68.049 & {$\left[\mathrm{C}_{4} \mathrm{H}_{6} \mathrm{~N}\right]^{+}$} & - & - & - \\
\hline & 71.049 & {$\left[\mathrm{C}_{4} \mathrm{H}_{7} \mathrm{O}\right]^{+}$} & - & - & - \\
\hline & 83.049 & {$\left[\mathrm{C}_{5} \mathrm{H}_{7} \mathrm{O}\right]^{+}$} & 0.361 & 0.558 & 0.048 \\
\hline \multirow[t]{3}{*}{8} & 69.033 & {$\left[\mathrm{C}_{4} \mathrm{H}_{5} \mathrm{O}\right]^{+}$} & 0.200 & 0.546 & 0.208 \\
\hline & 73.028 & {$\left[\mathrm{C}_{3} \mathrm{H}_{5} \mathrm{O}_{2}\right]^{+}$} & - & - & - \\
\hline & 99.044 & {$\left[\mathrm{C}_{5} \mathrm{H}_{7} \mathrm{O}_{2}\right]^{+}$} & - & - & - \\
\hline \multirow[t]{2}{*}{9} & 69.070 & {$\left[\mathrm{C}_{5} \mathrm{H}_{9}\right]^{+}$} & - & - & - \\
\hline & 73.065 & {$\left[\mathrm{C}_{4} \mathrm{H}_{9} \mathrm{O}\right]^{+}$} & 0.510 & 0.357 & 0.001 \\
\hline \multirow[t]{3}{*}{10} & 79.054 & {$\left[\mathrm{C}_{6} \mathrm{H}_{7}\right]^{+}$} & - & - & - \\
\hline & 81.033 & {$\left[\mathrm{C}_{5} \mathrm{H}_{5} \mathrm{O}\right]^{+}$} & 0.964 & 0.002 & 0.023 \\
\hline & 87.044 & {$\left[\mathrm{C}_{4} \mathrm{H}_{7} \mathrm{O}_{2}\right]^{+}$} & - & - & - \\
\hline \multirow[t]{4}{*}{11} & 85.028 & {$\left[\mathrm{C}_{4} \mathrm{H}_{5} \mathrm{O}_{2}\right]^{+}$} & Not used & Not used & Not used \\
\hline & 113.060 & {$\left[\mathrm{C}_{6} \mathrm{H}_{9} \mathrm{O}_{2}\right]^{+}$} & - & - & - \\
\hline & 137.060 & {$\left[\mathrm{C}_{8} \mathrm{H}_{9} \mathrm{O}_{2}\right]^{+}$} & - & - & - \\
\hline & 139.075 & {$\left[\mathrm{C}_{8} \mathrm{H}_{11} \mathrm{O}_{2}\right]^{+}$} & - & - & - \\
\hline \multirow[t]{2}{*}{12} & 89.060 & {$\left[\mathrm{C}_{4} \mathrm{H}_{9} \mathrm{O}_{2}\right]^{+}$} & - & - & - \\
\hline & 101.060 & {$\left[\mathrm{C}_{5} \mathrm{H}_{9} \mathrm{O}_{2}\right]^{+}$} & 0.659 & 0.008 & 0.148 \\
\hline \multirow[t]{3}{*}{13} & 103.039 & {$\left[\mathrm{C}_{4} \mathrm{H}_{7} \mathrm{O}_{3}\right]^{+}$} & - & - & - \\
\hline & 115.039 & {$\left[\mathrm{C}_{5} \mathrm{H}_{7} \mathrm{O}_{3}\right]^{+}$} & 0.235 & 0.382 & 0.274 \\
\hline & 141.055 & {$\left[\mathrm{C}_{7} \mathrm{H}_{9} \mathrm{O}_{3}\right]^{+}$} & - & - & - \\
\hline \multirow[t]{3}{*}{14} & 111.044 & {$\left[\mathrm{C}_{6} \mathrm{H}_{7} \mathrm{O}_{2}\right]^{+}$} & 0.019 & 0.485 & 0.010 \\
\hline & 113.023 & {$\left[\mathrm{C}_{5} \mathrm{H}_{5} \mathrm{O}_{3}\right]^{+}$} & - & - & - \\
\hline & 125.060 & {$\left[\mathrm{C}_{7} \mathrm{H}_{9} \mathrm{O}_{2}\right]^{+}$} & - & - & - \\
\hline \multirow[t]{2}{*}{15} & 129.055 & {$\left[\mathrm{C}_{6} \mathrm{H}_{9} \mathrm{O}_{3}\right]^{+}$} & 0.109 & 0.522 & 0.105 \\
\hline & 153.055 & {$\left[\mathrm{C}_{8} \mathrm{H}_{9} \mathrm{O}_{3}\right]^{+}$} & - & - & - \\
\hline 16 & 33.033 & {$\left[\mathrm{CH}_{5} \mathrm{O}\right]^{+}$} & 0.145 & 0.852 & 0.001 \\
\hline 17 & 34.995 & {$\left[\mathrm{H}_{3} \mathrm{~S}\right]^{+}$} & 0.000 & 0.651 & 0.120 \\
\hline 18 & 45.033 & {$\left[\mathrm{C}_{2} \mathrm{H}_{5} \mathrm{O}\right]^{+}$} & 0.094 & 0.771 & 0.082 \\
\hline 19 & 47.013 & {$\left[\mathrm{CH}_{3} \mathrm{O}_{2}\right]^{+}$} & 0.987 & 0.005 & 0.004 \\
\hline
\end{tabular}


Table 2 (continued)

\begin{tabular}{|c|c|c|c|c|c|}
\hline Family/ion trace no. & Th. & Sum formula & $\mathrm{PC} 1 \mathrm{R}^{2}$ & $\mathrm{PC} 2 \mathrm{R}^{2}$ & PC3 $\mathrm{R}^{2}$ \\
\hline 20 & 55.018 & {$\left[\mathrm{C}_{3} \mathrm{H}_{3} \mathrm{O}\right]^{+}$} & 0.104 & 0.574 & 0.108 \\
\hline 21 & 80.049 & {$\left[\mathrm{C}_{5} \mathrm{H}_{6} \mathrm{~N}\right]^{+}$} & 0.792 & 0.136 & 0.016 \\
\hline 22 & 97.028 & {$\left[\mathrm{C}_{5} \mathrm{H}_{5} \mathrm{O}_{2}\right]^{+}$} & 0.728 & 0.122 & 0.110 \\
\hline 23 & 117.055 & {$\left[\mathrm{C}_{5} \mathrm{H}_{9} \mathrm{O}_{3}\right]^{+}$} & 0.444 & 0.350 & 0.041 \\
\hline 24 & 145.050 & {$\left[\mathrm{C}_{6} \mathrm{H}_{9} \mathrm{O}_{4}\right]^{+}$} & 0.545 & 0.345 & 0.000 \\
\hline 25 & 37.028 & {$\left[\mathrm{H}_{5} \mathrm{O}_{2}\right]^{+}$} & Not used & Not used & Not used \\
\hline \multirow[t]{2}{*}{ Explained variance } & \multicolumn{2}{|c|}{ Calibration } & $71.9 \%$ & $96.8 \%$ & $98.4 \%$ \\
\hline & \multicolumn{2}{|c|}{ Cross-validation } & $68.1 \%$ & $96.0 \%$ & $97.7 \%$ \\
\hline
\end{tabular}

The highlighted ion traces correspond to the lead traces used to derive the predictive model (most intense ion traces from each family, in bold). Ion trace $\# 25$, the water cluster, was monitored only to assess the stability of the primary ion source $\left(\mathrm{H}_{3} \mathrm{O}^{+}\right)$and was not included into the predictive model. The table also includes the coefficient of determination for each principal component, PC1, PC2 and PC 3 , as well as the explained variance for the calibration and the cross-validation

the mass spectra. Whilst the lead trace of family \#1 shows similarities with the lead trace of family \#5, one observes a gradual increase in intensities already at a much earlier stage of the roasting process for the lead trace of family \#1. The lead trace of family \#24 exhibits a significantly different time-intensity pattern. After an initial increase, it reaches a maximum at approximately the same time as the plateau in $\# 5$, after which it decreases again, provided the roasting process is not halted at the maximum of the profile, as in the case of a light and medium roast with a high hotair inlet temperature. The concentration of the lead trace of family \#24 at the end of the roast process strongly depends on the hot-air inlet temperature. Another ion intensity-time profile which is shown in this figure is the ion trace of the water cluster $\left[\mathrm{H}_{5} \mathrm{O}_{2}\right]^{+}$. The intensity of this ion trace is slightly dependent on the humidity of the roast off-gas and reflects initially (1) the first phase of the roasting process during which the beans are drying and later (2) the evaporation of water generated in the exothermic condensation reactions of the Maillard and Strecker reactions. Three of these and the other significant ion traces (as listed in Table 2) were used to build a predictive model based on PCA.

Process control via the projection at real-time PTR-ToF-MS data onto a 3D PCA space

To understand the relationships between the ion traces and the roasting profiles, a PCA was performed using the 'The Unscrambler X v10.1' Software, Camo (www.camo.com) $[35,36]$. PCA is a mathematical procedure that uses an orthogonal transformation to convert a set of observations of possibly correlated variables into a set of values of uncorrelated (orthogonal) variables called principal components. This transformation is defined in such a way that the first principal component has the highest possible variance.
Each succeeding component in turn has the highest variance possible under the constraint that it be orthogonal to the preceding components.

Only the intensities of the lead traces at the end points of the roasting processes were used to set up the predictive model (see Table 2). Because a higher hot-air inlet temperature leads to a higher VOC concentration in the off-gas, which in turn would have a too strong impact on the first principal components of the PCA, the data were normalized according to Eq. 2 by dividing the respective intensities ncps Ion $_{\text {In }}$ by the intensity of compound \#5, $\mathrm{ncps}_{\left[\mathrm{C}_{2} \mathrm{H}_{5} \mathrm{O}_{2}\right]^{+}}$, which was throughout all trials the most intense $\mathrm{m} / \mathrm{z}$ trace. This strongly improved the quality of the predictive model.

$\mathrm{I}_{\text {Ion }}=\frac{\mathrm{ncps}_{\text {Ion }} / \mathrm{kg}}{\mathrm{ncps}_{\left[\mathrm{C}_{2} \mathrm{H}_{5} \mathrm{O}_{2}\right]^{+}} / \mathrm{kg}}$

For the development of the predictive model, the mass spectra in terms of $I_{\text {Ion }}$ for the 24 lead traces (excluding $\left.\left[\mathrm{H}_{5} \mathrm{O}_{2}\right]^{+}\right)$at the end points of each of the 42 roasting trials were used to derive the first model of the PCA. In addition, another model was established, with the lead trace \#11 being excluded since the sum of the coefficients of determination from the first three principal components (PCs) was not higher than the threshold level of 0.5 (not significant). As shown in Fig. 6a, b, this led to a clear separation of hot-air inlet temperature as well as of the roast degree in the space of the first three principal components PC1, PC2 and PC3, which explain $98.4 \%$ of the variance. The explained variance of the cross-validation is similar to that of the calibration, reflecting the high quality of the model. Table 2 shows the impact of the respective ion traces on the principal components. PC1 clearly separates between light (inverted triangle), medium (square) and dark (circle) roast degrees. The second principal component 

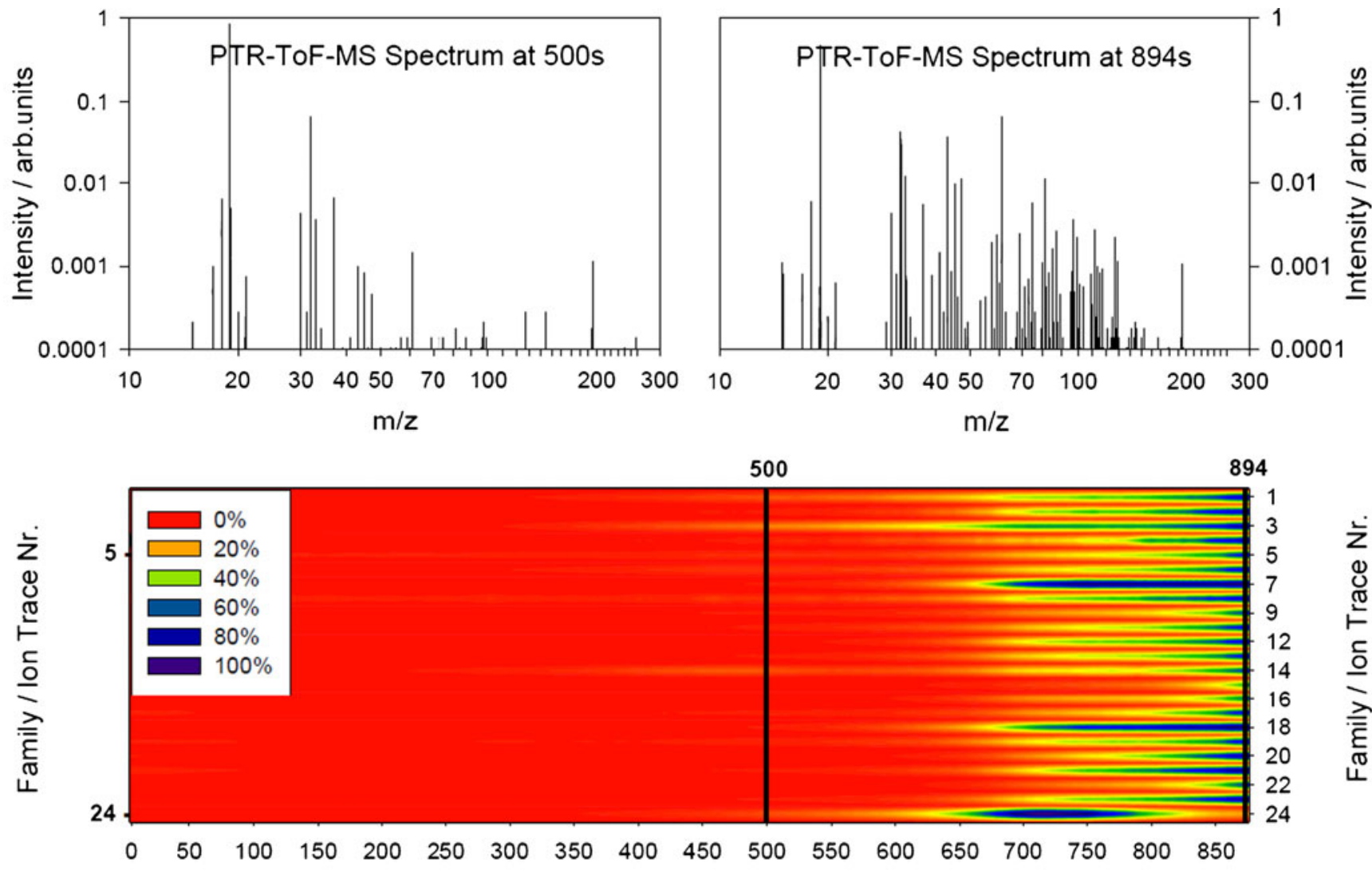

Time / s

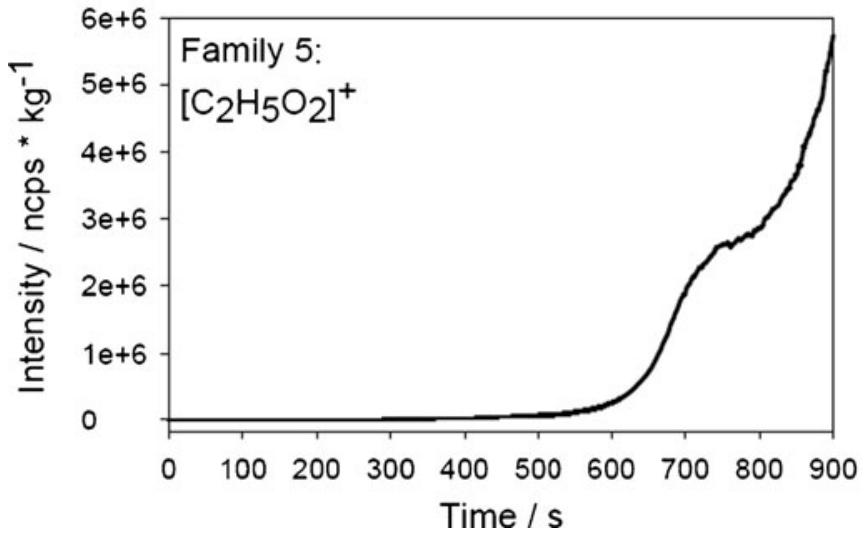

Fig. 4 Typical data set for medium hot-air inlet temperature and dark roast $(M D)$ corresponding to a total roasting time of $894 \mathrm{~s}$. Top, PTRToF-MS $\mathrm{m} / \mathrm{z}$ spectra in a logarithmic scale at $500 \mathrm{~s}$ (left) and $894 \mathrm{~s}$ (right, end of the roasting process), as indicated in the central contour plot by two vertical bars at the respective times. Central, Full time-

(PC2) separates the roasting experiments with a high hot-air inlet temperature (black) from those with a medium (grey) and low (white) hot-air inlet temperature. Finally, PC3 separates roasting experiments with a medium (red) from those with low (green) hot-air inlet temperatures. Hence, within the 3D space of the first three principal components, the nine different roasting processes can be clearly separated. This is demonstrated in Fig. 6c, where all 42

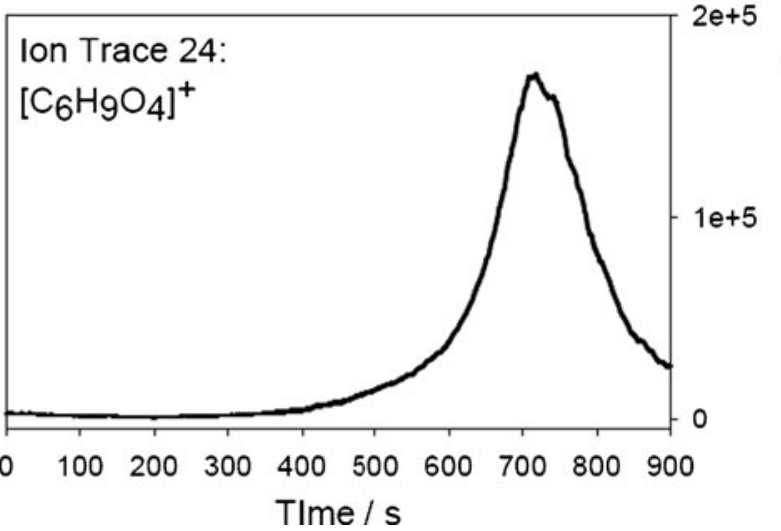

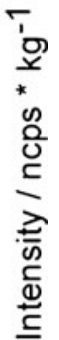

intensity contour plot for the 23 traces used for the predictive model. Bottom, Horizontal cuts of the contour plot: time-intensity profiles of (left) lead trace \#5 (61.028 Th. $\left.\left[\mathrm{C}_{2} \mathrm{H}_{5} \mathrm{O}_{2}\right]^{+}\right)$and (right) lead trace \#24 (145.050 Th. $\left.\left[\mathrm{C}_{6} \mathrm{H}_{9} \mathrm{O}_{4}\right]^{+}\right)$

calibration points of the roasts were plotted in the 3D space of the axes PC1, PC2 and PC3.

In addition to these points, Fig. $6 \mathrm{c}$ shows the trace of an actual roasting process at medium hot-air inlet temperature to a dark roast degree (MD profile). The online-monitored $I_{\text {Ion }}$ for the 23 lead traces were projected in real time onto the PCA space defined by the 42 calibration points, displaying a trajectory that reflects the progress of the 

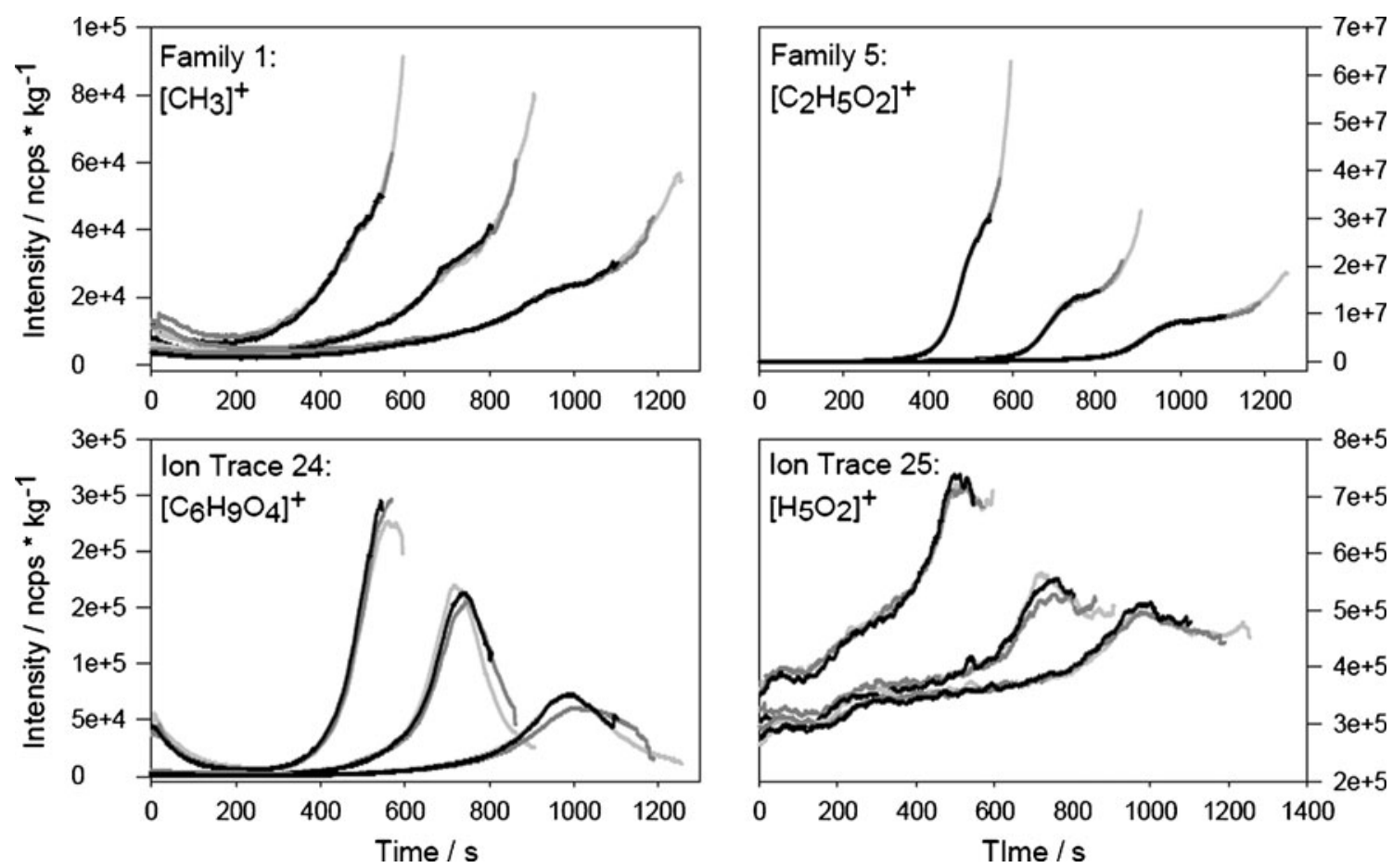

Fig. 5 The lead traces of four different compounds are shown: top left, family $1,\left[\mathrm{CH}_{3}\right]^{+}$; top right, family $5,\left[\mathrm{C}_{2} \mathrm{H}_{5} \mathrm{O}_{2}\right]^{+}$; bottom left, ion trace $\# 24,\left[\mathrm{C}_{6} \mathrm{H}_{9} \mathrm{O}_{4}\right]^{+}$; bottom right, ion trace $\# 25,\left[\mathrm{H}_{5} \mathrm{O}_{2}\right]^{+}$. For each

compound, nine traces are shown. The dark black line represents traces to a light roast, the medium grey line to a medium roast and the light grey line to a dark roast

roasting process. In Fig. 6c, the trajectory is plotted from $450 \mathrm{~s}$ onwards, after having started the roasting process.

A closer look reveals two striking discontinuities in the trajectories of the roasting process in the PCA space. The first one appears at $625 \mathrm{~s}$ and the second at $730 \mathrm{~s}$, both being characterized by changes in the VOC profile of the 23 lead traces sampled in the off-gas of the roaster. Roast time of $625 \mathrm{~s}$ marks the transition from the initial endothermic drying process of the green beans (during which some flavour precursor may already be forming) to the exothermic roasting phase where Maillard reactions lead to the formation of the typical volatile coffee aroma compounds and the appearance of VOC at larger $\mathrm{m} / \mathrm{z}$. At $730 \mathrm{~s}$, the second discontinuity in the trajectory, one starts
Fig. 6 PCA based on all normalized lead traces, as highlighted in Table 2. Inverted triangles mark the dark roast degree, square medium and circle light, respectively. The hot-air inlet temperature is marked as follows: high (black), medium (grey), low (white). a The 2D space of the first two principal components PC1 and PC2 with the 42 calibration points used to derive the PCA. b Analogous space for PC1-PC3. c Combines the three first principal components in a $3 \mathrm{D}$ space and demonstrates that the different hot-air inlet temperatures and roast degrees are clearly separated. It also shows the realtime projection of a roasting process at medium hot-air inlet temperature to a dark roast $(M D)$
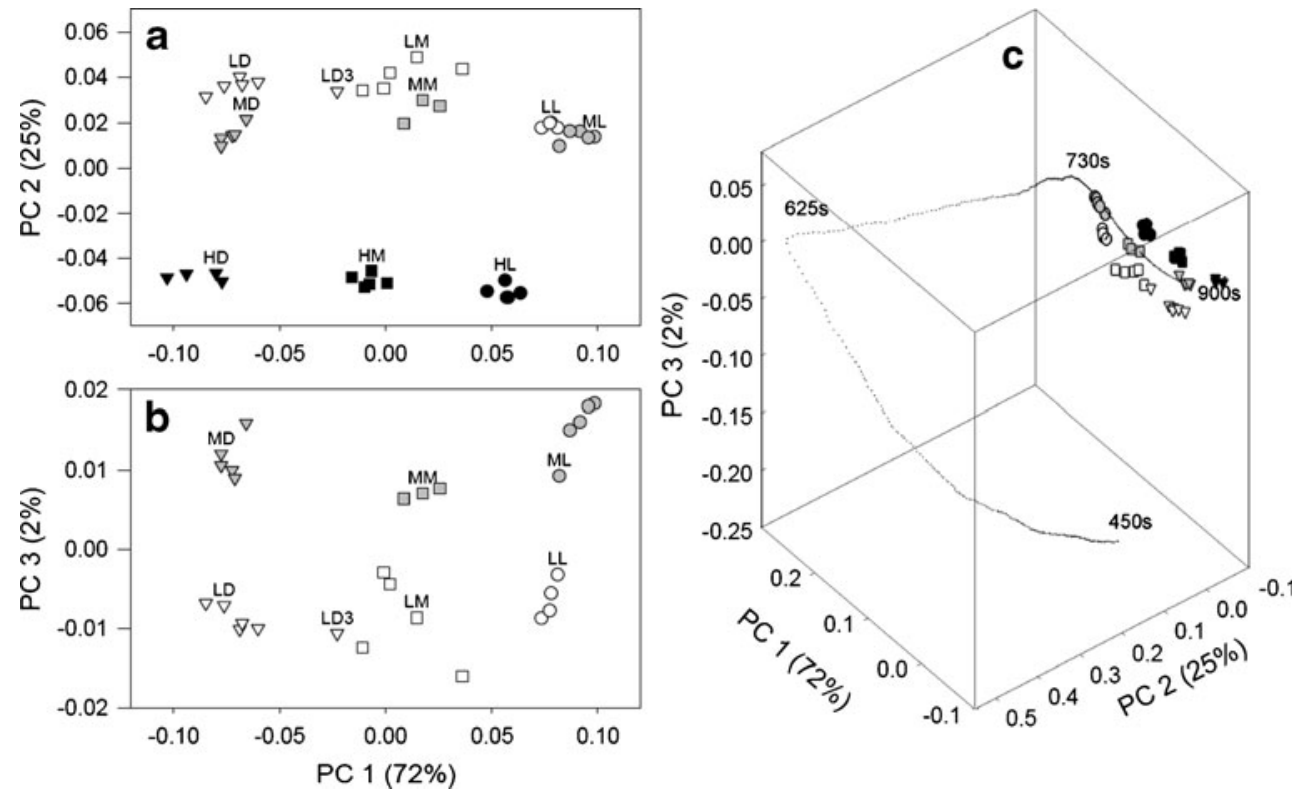
to observe either the onset of a plateau in a series of $\mathrm{m} / \mathrm{z}$ time-intensity profiles (e.g. lead trace \#5) or a maximum in the time-intensity profile for certain $\mathrm{m} / \mathrm{z}$ traces (e.g. lead trace \#24), simultaneously with the first crack. After the first crack, the roasting evolved along a section of the PCA trajectory that is rather smooth and represents the critical phase of the coffee roasting process. It is marked by a large number of calibration points that allow predicting, from the online-monitored VOC profile in the off-gas, the real-time volatile profile and the concomitant roasting degree with a precision better than \pm 1 Colorette.

Considering that the time resolution is set to $1 \mathrm{~Hz}$, this opens the possibility for a precise monitoring of the evolution of the roasting process and a tight control and consistency of the end point of the roast, batch after batch.

\section{Conclusions}

The work proposed here introduced an analytical technology and a statistical methodology that allows predicting in real time and with a precision better than \pm 1 Colorette (at a fixed hot-air inlet temperature) the roast degree all along the coffee roasting process.

In a first calibration step, a predictive model is developed based on a series of 42 roasting experiments at three fixed hot-air inlet temperatures to various roast degrees. The roaster off-gas is monitored online by PTRToF-MS, at a high time $(1 \mathrm{~Hz})$ and mass resolution $(5,500 \mathrm{~m} / \Delta \mathrm{m}$ at FWHM) and high sensitivity (better than parts per billion by volume). Based on a multistep data filtering and analysis process, 23 specific time-intensity ion traces (lead traces) were selected. Using these, a 3D PCA space was constructed that separates the three hot-air inlet temperatures and allows, for each hot-air inlet temperature, to achieve a resolution in the roast degree of better than \pm 1 Colorette.

In a second step, the PCA model was applied to predict the roast degree in real time. The online-monitored and normalized intensities of the 23 pre-selected lead traces were projected in real time onto the 3D space of the three first principal components of the PCA defined in the first step. These allowed following precisely the evolution of the roasting process and terminating the roast at the exactly desired roast degree.

This research demonstrates that a time-resolved analysis of the VOC profiles in the off-gas by PTR-ToF-MS provides a detailed picture of the evolution of the roasting process and allows establishing a real-time process control tool that ensures the highest consistency of the roast.

In view of potential industrial applications, we will also explore in subsequent studies whether the same quality of process control can be achieved with a less sophisticated and expensive PTR-MS, equipped with a quadrupole mass spectrometer, and achieves a much lower mass resolution.

Acknowledgement We acknowledge Bühler AG for financial support.

\section{References}

1. Pendergrast M (2009) Coffee second only to oil? Is coffee really the second largest commodity? Tea Coffee Trade J 181:38-41

2. Schenker S, Perren R, Escher F, Heinemann C, Huber M, Pompizzo R (2002) Impact of roasting conditions on the formation of aroma compounds in coffee beans. J Food Sci 67 (1):60-66

3. Baggenstoss J, Poisson L, Kaegi R, Perren R, Escher F (2008) Coffee roasting and aroma formation: application of different time-temperature conditions. J Agric Food Chem 56(14):58365846

4. Moon JK, Shibamoto T (2009) Role of roasting conditions in the profile of volatile flavor chemicals formed from coffee beans. J Agric Food Chem 57(13):5823-5831

5. Sivetz M, Desrosier NW (1979) Coffee bean processing. In: Coffee technology. AVI Publishing, Westport, pp 209-278

6. Gutierrez-Osuna R (2002) Pattern analysis for machine olfaction: a review. IEEE Sens J 2(3):189-202

7. Biasioli F, Yeretzian C, Dewulf J, van Langenhove H, Märk T (2011) Direct injection mass spectrometry (DIMS): adding the time dimension to (B)VOC analysis. Trac-Trends Anal Chem 30(7):1003-1017

8. jublot L, Linforth RST, Taylor AJ (2005) Direct atmospheric pressure chemical ionisation ion trap mass spectrometry for aroma analysis: speed, sensitivity and resolution of isobaric compounds. Int J Mass Spec 243(3):269EP-277EP

9. Taylor AH, Linforth RST (2003) Direct mass spectrometry of complex volatile and non-volatile flavour mixtures. Int $\mathrm{J}$ Mass Spec 223-224:179-191

10. Taylor AJ (1996) Volatile flavor release from foods during eating. CRC Crit Rev Food Sci Nutr 36(8):765-784

11. Linforth RST, Savary I, Pattenden B, Taylor AH (1994) Volatile compounds found in expired air during eating of fresh tomatoes and in the headspace above tomatoes. J Sci Food Agric 65:241247

12. Linforth RST, Taylor A (1993) Measurement of volatile release in the mouth. Food Chem 48:115-120

13. Yeretzian C, Jordan A, Brevard H, Lindinger W (2000) Timeresolved headspace analysis by proton-transfer-reaction massspectrometry. In: Roberts DD, Taylor AJ (eds) ACS Symposium Series 763. ACS, Washington, pp 58-72

14. Lindinger W, Hansel A, Jordan A (1998) Proton-transfer-reaction mass spectrometry (PTR-MS): on-line monitoring of volatile organic compounds at pptv levels. Chem Soc Rev 27:347-354

15. Lindinger W, Hansel A, Jordan A (1998) On-line monitoring of volatile organic compounds at pptv levels by means of protontransfer-reaction mass spectrometry (PTR-MS): medical applications, food control and environmental research. Int J Mass Spectrom Ion Process 173:191-241

16. Lindinger W, Hansel A (1997) Analysis of trace gases at ppb levels by proton transfer reaction mass spectrometry (PTR-MS). Plasma Sources Sci Technol 6:111-117

17. Hansel A, Jordan A, Holzinger R, Prazeller P, Vogel W, Lindinger W (1995) Proton transfer reaction mass spectrometry: on-line trace gas analysis at the ppb level. Int J Mass Spectrom Ion Process 149/150:609-619 
18. Lindinger C, Pollien P, Ali S, Yeretzian C, Märk T (2005) Unambiguous identification of volatile organic compounds by proton-transfer reaction mass spectrometry coupled with GC/MS. Anal Chem 77(13):4117-4124

19. Lindinger C, Labbe D, Pollien P, Rytz A, Juillerat MA, Yeretzian C, Blank I (2008) When machine tastes coffee: instrumental approach to predict the sensory profile of espresso coffee. Anal Chem 80(5):1574-1581

20. Blake RS, Monks PS, Ellis AM (2009) Proton-transfer reaction mass spectrometry. Chem Rev 109(3):861-896

21. Hanley L, Zimmermann R (2009) Light and molecular ions: the emergence of vacuum UV single-photon ionization in MS. Anal Chem 81(11):4174-4182

22. Geissler R, Saraji-Bozorgzad MR, Groêger T, Fendt A, Streibel T, Sklorz M, Krooss BM, Fuhrer K, Gonin M, Kaisersberger E, Denner T, Zimmermann R (2009) Single photon ionization orthogonal acceleration time-of-flight mass spectrometry and resonance enhanced multiphoton ionization time-of-flight mass spectrometry for evolved gas analysis in thermogravimetry: comparative analysis of crude oils. Anal Chem 81(15):6038-6048

23. Muhlberger F, Hafner K, Kaesdorf S, Ferge T, Zimmermann R (2004) Comprehensive on-line characterization of complex gas mixtures by quasi-simultaneous resonance-enhanced multiphoton ionization, vacuum-UV single-photon ionization, and electron impact ionization in a time-of-flight mass spectrometer: setup and instrument characterization. Anal Chem 76(22):6753-6764

24. Dorfner R, Ferge T, Yeretzian C, Kettrup A, Zimmermann R (2004) Laser mass spectrometry as on-line sensor for industrial process analysis: process control of coffee roasting. Anal Chem 76 (5):1386-1402

25. Dorfner R, Ferge T, Kettrup A, Zimmermann R, Yeretzian C (2003) Real-time monitoring of 4-vinylguaiacol, guaiacol and phenol during coffee roasting by resonant laser ionisation timeof-flight mass-spectrometry. J Agric Food Chem 51(19):57685773

26. Mühlberger F, Wieser J, Ulrich A, Zimmermann R (2002) Single photon ionization (SPI) via incoherent VUV-excimer light: robust and compact time-of-flight mass spectrometer for on-line, realtime process gas analysis. Anal Chem 74:3790-3801
27. Dorfner R, Ferge T, Uchimura T, Yeretzian C, Zimmermann R, Kettrup A (2002) Laser/chemical ionisation - mass spectrometry as an on-line analysis technique for monitoring the coffee roasting process. ASIC-19eme Colloque Scientifique International sur le Café, ASIC, Paris

28. Zimmermann R, Heger HJ, Kettrup A, Boesl U (1997) A mobile resonance-enhanced multiphoton ionization time-of-flight mass spectrometry device for on-line analysis of aromatic pollutants in waste incinerator flue gases: first results. Rapid Commun Mass Spectrom 11(10):1095-1102

29. Heger HJ, Zimmermann R, Dorfner R, Beckmann M, Griebel H, Kettrup A, Boesl U (1999) On-line emission analysis of polycyclic aromatic hydrocarbons down to pptv concentration levels in the flue gas of an incineration pilot plant with a mobile resonance-enhanced multiphoton ionization time-of-flight mass spectrometer. Anal Chem 71:46-57

30. Zimmermann R, Heger HJ, Yeretzian C, Nagel H, Boesl U (1996) Application of laser ionization mass spectrometry for on-line monitoring of volatiles in the headspace of food products: roasting and brewing of coffee. Rapid Commun Mass Spectrom 10:1975-1979

31. Yeretzian C, Jordan A, Badoud R, Lindinger W (2002) From the green bean to the cup of coffee: investigating coffee roasting by online monitoring of volatiles. Eur Food Res Technol 214:92-104

32. Yeretzian C, Jordan A, Brevard H, Lindinger W (2000) On-line monitoring of coffee roasting by proton-transfer-reaction massspectrometry. In: Roberts DD, Taylor AJ (eds) ACS Symposium Series 763. ACS, Washington, pp 112-123

33. Dorfner R, Zimmermann R, Kettrup A, Yeretzian C, Jordan A, Lindinger W (1999) Vergleich zweier massenspektrometrischer Verfahren zur Direktanalyse in der Lebensmittelchemie. Lebensmittelchemie 53:32-34

34. Friedman JH (1984) A variable span scatterplot smoother. Laboratory for Computational Statistics

35. Esbensen KH, Guyot D, Westad F, Houmøller LP (2002) Multivariate data analysis: in practice: an introduction to multivariate data analysis and experimental design, 5th edn. CAMO Software AS, Oslo

36. Kessler W (2007) Multivariate datenanalyse in der bio- und prozessanalytik. Wiley-VCH, Weinheim 